\title{
Assessment and modeling of chlorine release in urban region: A case study in water supply of Eyvan city, Iran
}

\author{
Seyyed Hossein Hosseini ${ }^{1 *}$
}

1. Department of Chemical Engineering, Faculty of Engineering, Ilam University, Ilam, Iran

*Corresponding author: Tel: +98 9137944470 Fax: +98 8432227029

Address: Department of Chemical Engineering, Faculty of Engineering, Ilam University, Ilam, Iran

E-mail: s.h.hosseini@ilam.ac.ir

Received; 2015/07/12 revised; 2015/07/20 accepted; 2015/08/26

\begin{abstract}
Introduction: Today, with development of various industries, the adverse events originated from explosion and emission of toxic and chemical substances have increased. These events may cause serious environmental problems that threaten human health and safety. Therefore, knowledge about the risk of toxic substances from industrial facilities is essential. Although, chlorine is extensively utilized in water treatment as a disinfectant and some chemical processes as an oxidizing agent, it can lead to some concerns in environmental issues.

Materials and methods: In this study, distribution of chlorine in the water supply of Eyvan city from Ilam province, Iran, and its surrounding areas is evaluated and high-risk regions are defined by Process Hazard Analysis Software Tool (PHAST) specialized software.

Results: The modeling results showed that the cloud of chlorine is about $1220 \mathrm{~m}$ across just downwind of the release for the first scenario (rupture of a chlorine vessel) in the summer; however, the probability of fatality is $100 \%$ in a whole year in a distance of $40 \mathrm{~m}$ from the vessel. For the second scenario (rupture of pipeline including the chlorine gas) the human death mostly occurs in a distance of $25 \mathrm{~m}$ from the pipeline with the probability of $2.8 \%$ in the summer due to low rate of released gas.

Conclusion: As an important result, the land around the chlorination unit covering a distance of approximately $1220 \mathrm{~m}$ is vulnerable and risk prevention in that region should be accounted for.
\end{abstract}

Keywords: Consequence assessment, Chlorine release, Modeling, PHAST

\section{Introduction}

There are many toxic materials in chemical industry that can harm human health (1-3). Many incidents have appeared in chemical storage sites in the recent years with considerable consequences for neighboring populations $(4,5)$. In this regards, a large number of researches have been carried out to define the level of risk and the possible impact to the surroundings for certain port areas (6-9).

The science of risk assessment is welldefined as a process, in which both qualitative and quantitative risks and their social evaluations are determined $(10,11)$. Whereas, the consequence is the result of an accident such as being a loss, injury, and weakness or gain. Consequence Analysis is an important part in chemical process quantitative risk analysis (CPQRA). In addition to CPQRA, consequence analysis can be useful for many other purposes such as determining an optimum location on plant, defining equipment design parameters, identification of potential impacts on adjacent facilities, and assistance in emergency response and etc. (12). This analysis is used for various chemical materials such as toxic, flammable and explosion materials (13). 
Chlorine is an essential material to protect human from outbreaks of waterborne disease (14). Population growth and developing the water treatment technology make extensive use of consequence analysis for prediction and prevent the harmful effects of chlorine release in chemical plants. There are various commercial codes including Gaussian model for consequence analysis of risk, such as SLAB, ALOHA, PHAST, and etc. (15). Some required data for a Gaussian model are wind speed, atmospheric stability, height of the release above the ground, momentum of the material released and buoyancy, and surface roughness. Besides the mentioned agents, the population distribution around the desired industrial unit can be critical (12).

PHAST software, which presents the best model for gas dispersion in outdoor environment, is a comprehensive consequence analysis tool in the field. By this software various release scenarios such as leaks, line ruptures, long pipeline releases and tank roof collapse in pressurized/unpressurised vessels or pipes can be modeled accurately (16).

This present study is particularly focused on determining and identifying the locations with high risk near the water treatment plant of Eyvan city from Ilam province, Iran. The PHAST software is used for modeling the chlorine release. All possible scenarios are considered for real chlorine plant and the results are evaluated to determine the safety perimeters around industrial sites.

\section{Materials and methods}

The initial conditions given to the instantaneous and continuous discharge models depend on the source of release and accidental event. In a consequence model the initial conditions for a release are set by defining characteristics of the release and the failed equipment. The material before release is stored in a vessel under pressurised conditions. The initial conditions are specified by the temperature, pressure, and chlorine phase. Pressurised storage conditions are appeared for the gases held in pressure vessels containing only vapour phase and finally for the vessels including the pure saturated liquid phase.

Stability: Passive dispersion is strongly affected by atmospheric stability. For dispersion modelling, the rate of change of temperature with height considerably affects the dispersion for both unstable and stable conditions. It is not necessary to know the rate of temperature change with height; it depends on the daytime insolation (i.e. sunshine reaching the ground) or night time cloud cover and on the wind speed. Besides the standard wind-rose information on wind speed and direction, the dispersion of release is reliant on the atmospheric stability. Whereas atmospheric conditions are classified according to six Pasquill stability classes (denoted by the letters AF). The stability classes are mainly correlated to wind speed and the quantity of sunlight.

The stability classes are mainly correlated to wind speed and the quantity of sunlight. Gaussian Model: Most industrial accidents occur due to release of toxic material. The various parameters affect the discharge modeling of these materials such as full diameter of rupture, material phase and its amount, etc. The goal of material release modeling is prediction of dispersed concentration at specified distance and time. These models are acceptable in accuracy and have many applications in release modeling.

This model is based on the following partial equation that is obtained from the mass conservation equation by:

$$
\frac{\partial C}{\partial t}+\frac{\partial}{\partial x_{j}}\left(u_{j} \cdot C\right)=0
$$

$\mathrm{C}$ is material concentration, $\mathrm{u}$ is wind velocity and $\mathrm{j}$ shows direction of $\mathrm{X}, \mathrm{Y}$ and $\mathrm{Z}$. Concentration in continues release is given by: 


$$
[C](x, y, z)=\frac{Q_{m}}{2 \pi \sigma_{y} \cdot \sigma_{z}} \cdot \exp \left[-\frac{u}{2}\left(\frac{y}{\sigma_{y}}\right)^{2}\right] \times\left\{\exp \left[-\frac{u}{2}\left(\frac{z-H_{r}}{\sigma_{z}}\right)^{2}\right]+\exp \left[-\frac{u}{2}\left(\frac{z+H_{r}}{\sigma_{z}}\right)^{2}\right]\right\}
$$

And in flash release is calculated by:

$[C](x, y, z, t)=\frac{Q_{m}}{(2 \pi t)^{1.5} \cdot \sigma_{x} \cdot \sigma_{y} \cdot \sigma_{z}} \cdot \exp \left[-\frac{u}{2}\left(\frac{y}{\sigma_{y}}\right)^{2}\right] \times\left\{\exp \left[-\frac{u}{2}\left(\frac{z-H_{r}}{\sigma_{z}}\right)^{2}\right]+\exp \left[-\frac{u}{2}\left(\frac{z+H_{r}}{\sigma_{z}}\right)^{2}\right]\right\}$

Maximum concentration also is calculated by equation (4) as follows:

$$
[C]_{\max }=\frac{2 Q_{m}}{e \pi u H^{2}}\left(\frac{\sigma_{z}}{\sigma_{y}}\right)
$$

Water Treatment Plant of Eyvan city: Water treatment plant located at Eyvan city provides drinking water of this town, thus, the establishment of such a plant in that region is necessary. This unit including only one chlorination line is located in a populated area with about more than 30,000 populations.

As mentioned before, a consequence assessment requires information of the local population distribution to calculate the risk consequence for the different failure cases. The consequence results are most sensitive to the assumptions of population, which are most exposed to potential releases.

In this study, two scenarios of rupture vessel and pipeline are evaluated particularly in terms of probability of fatality. The hole diameters of $5 \mathrm{~mm}$ and 25 $\mathrm{mm}$ are selected for the case of second scenario. Regarding the operating conditions of chlorine plant, it should be noted that the temperature and volume of chlorine vessel are $0.638 \mathrm{~m}^{3}$ and $66.83{ }^{\circ} \mathrm{C}$, respectively. In addition, the mass flow rate of chlorine in pipeline is equal to $4.2 \times 10^{-5}$ $\mathrm{kg} / \mathrm{s}$ and the immediately dangerous to life and health (IDLH) factor of $30 \mathrm{ppm}$ is considered for chlorine. Finally, the climate information of Eyvan is listed in Tables 1.

IDLH is concentration limit for toxic relevant to gaseous compound or vapors.
These levels have been previously recognized by the national institute for occupational safety and health (NIOSH) as the concentration from which one could escape within $30 \mathrm{~min}$ without any escapeimpairing symptoms or any irreversible health effects (17). This concentration for chlorine has been measured by NIOSH, and found to be equal to $30 \mathrm{ppm}$.

\section{Results}

It is noticeable that chlorine is mainly used for disinfection of drinking-water in this plant. Since chlorine is a toxic material, thus, its dispersion can be dangerous for human health. In the present study, the PHAST software is used for modeling of chlorine release. After running of this software fourteen diagrams including maximum concentration footprint, probity versus distance and probability of fatality are obtained for each scenario, which only some of them are compared together in this paper for sake of brevity. Figure $1(a, b)$ shows the maximum cloud concentration footprint in different areas from the top view for rupture of chlorine vessel and pipeline in four seasons. In this figure the regions with red, yellow, green and blue colors show the winter, autumn, summer and spring seasons, respectively. Figure 1(a) shows that the cloud of chlorine with concentration more than $30 \mathrm{ppm}$, is appeared at $1220 \mathrm{~m}$ downwind distance for rupture of chlorine vessel in the summer, while Figure 1(b) shows the corresponding term at $46.5 \mathrm{~m}$ downwind distance for rupture of chlorine pipeline in summer. 


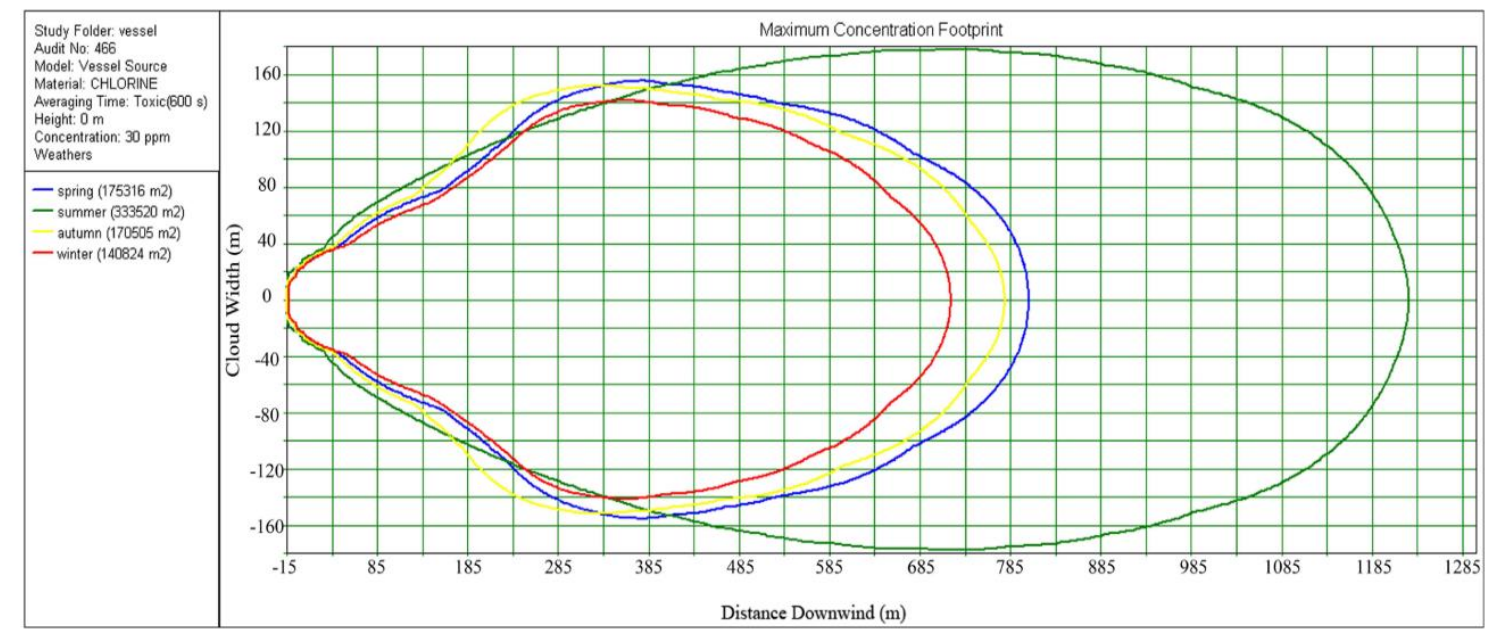

(a)

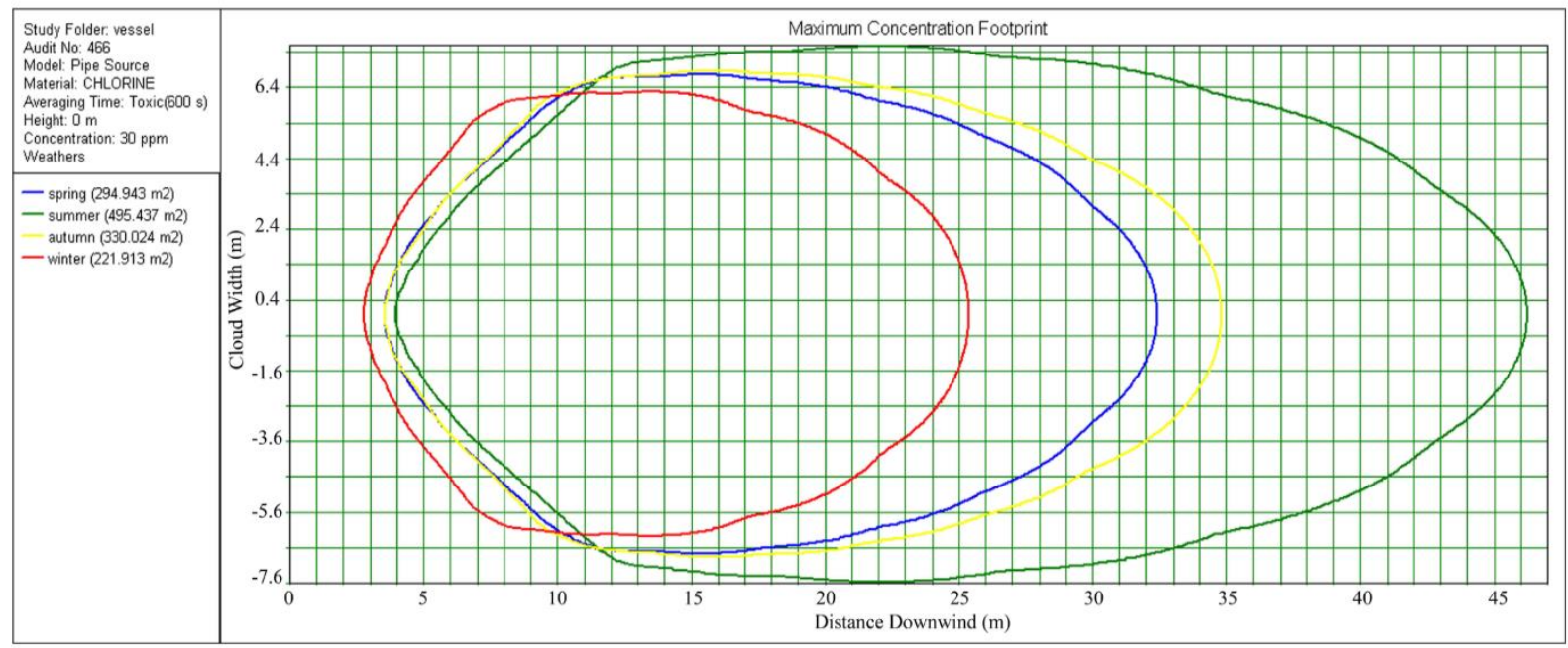

(b)

Figure 1. Maximum concentration footprint for rupture of: (a) chlorine vessel (b) chlorine pipeline in four seasons.

Figure 2 shows the maximum concentration footprint of chlorine on the Eyvan city map. This figure is prepared based on the first scenario in four seasons and shows that the maximum concentration of chlorine occurs at the border town. Moreover, for the first scenario, concentration of chlorine reaches to its maximum values at 61.56 and 25.41 seconds after rupture of chlorine cylinder in summer and winter, respectively. But in the second scenario, maximum concentration of chlorine is very lower than the former and occurs at 5.65 and 2.45 seconds after rupture of pipeline in summer and winter, respectively, which cannot be seen in the figure due to insignificant area relevant to this scenario Figure 3(a, b) shows the probability of fatality for rupture of chlorine vessel and pipeline, respectively, versus downwind distance for all seasons. Figure 3(a) shows that the probability of fatality is $100 \%$ at outdoor release at $40 \mathrm{~m}$ downwind distance in all seasons for the first scenario, i.e. rupture of chlorine vessel. As shown in Figure 3(b), the probability of fatality is $2.8 \%$ at outdoor release in summer at $25 \mathrm{~m}$ downwind distance for the second scenario, i.e. rupture of chlorine pipeline. In addition green, blue and red curves represent the probability of fatality versus downwind distance in autumn, spring and winter seasons, respectively. 


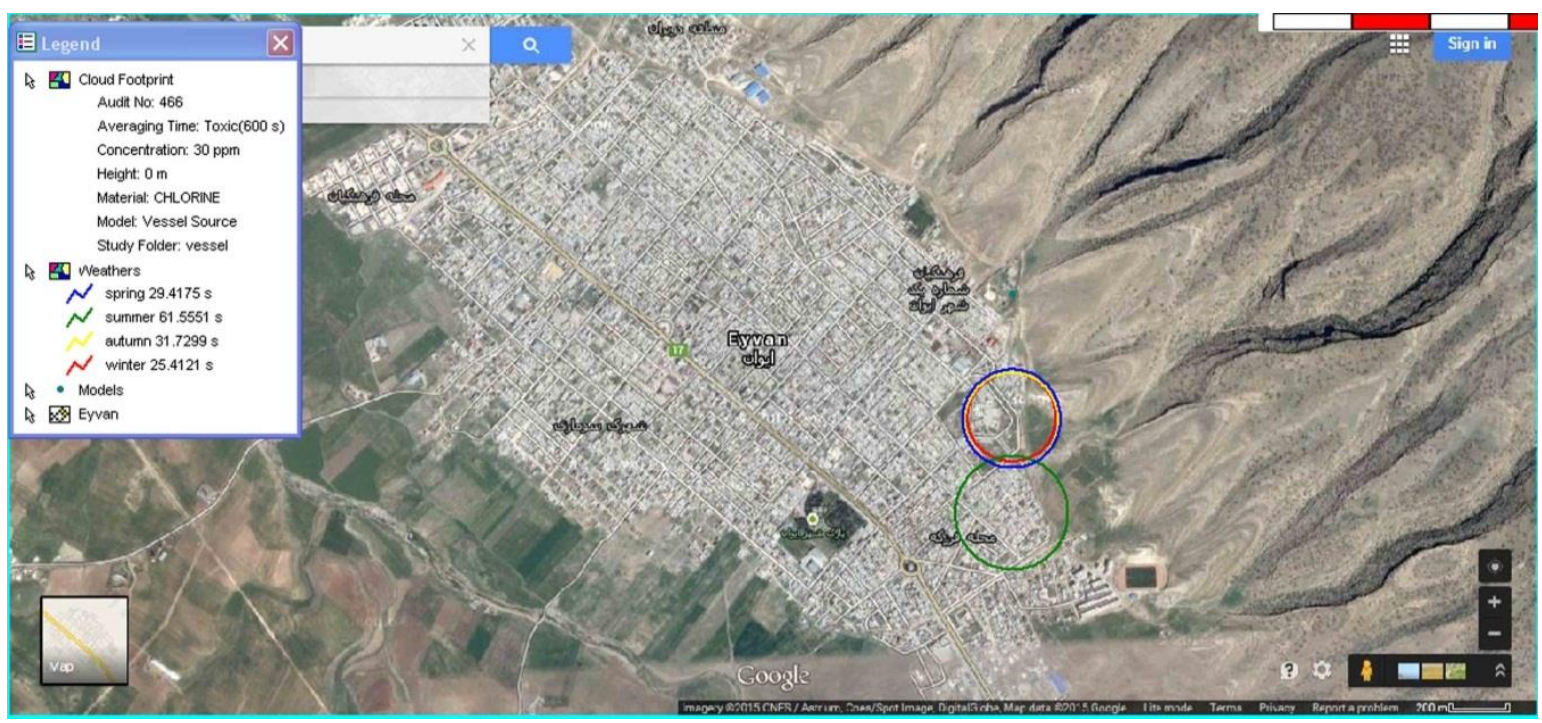

Figure 2. Maximum concentration footprint of chlorine on the Eyvan map for rupture of vessel.

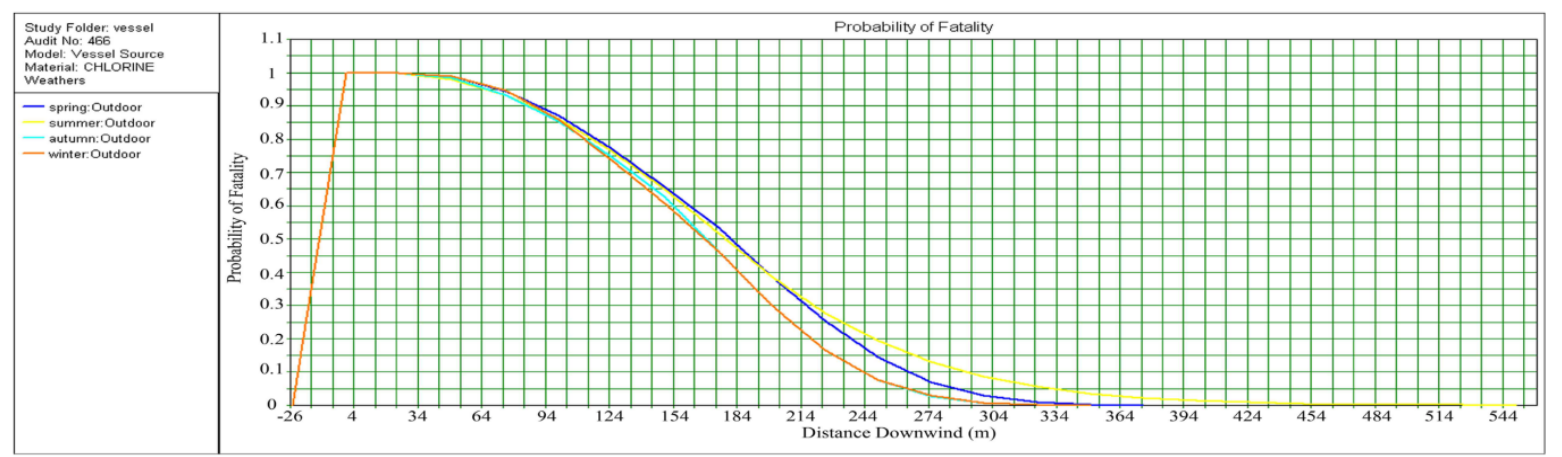

(a)

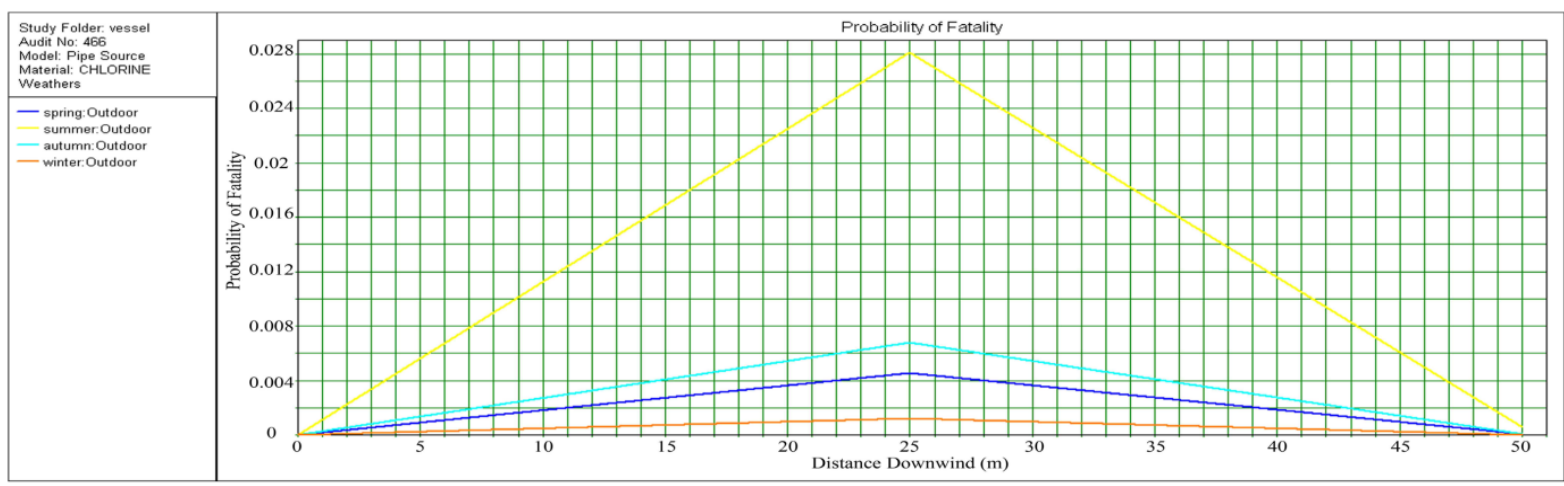

(b)

Figure 3. Probability of fatality for rupture of: (a) chlorine vessel (b) chlorine pipeline in four seasons.

The consequence modeling results are summarized in Table 2. According to the simulation results, maximum downwind distances of chlorine release in summer, spring, autumn and winter are appeared in $1220,805,780$, and $720 \mathrm{~m}$ from the vessel, respectively, for the first scenario. Almost the same results are achieved for the second scenario, i.e. in the case of rupture of pipeline, maximum downwind distances of chlorine release in summer, spring, autumn and winter are appeared in 46.5, 32.5, 34, and $25.5 \mathrm{~m}$, respectively. Moreover, some useful information such as maximum height of chlorine cloud and maximum width of chlorine cloud are listed in this table. 
Table 1. Climate information.

\begin{tabular}{lcccc}
\hline Seasons & Atmospheric Stability Class & Average temperature $\left({ }^{\circ} \mathrm{C}\right)$ & Humidity $(\%)$ & Wind Speed $(\mathrm{m} / \mathrm{s})$ \\
\hline Spring & B, C & 18.06 & 35.7 & 13 \\
Summer & C & 25.5 & 17 & 10.7 \\
Autumn & B, C & 13.7 & 45 & 12 \\
Winter & B & 9.85 & 70 & 14 \\
\hline
\end{tabular}

Table 2. The results of consequence modeling.

\begin{tabular}{llccccc}
\hline Scenario & Seasons & $\begin{array}{l}\text { Maximum height of } \\
\text { chlorine cloud }(\mathrm{m})\end{array}$ & $\begin{array}{l}\text { Maximum distance of } \\
\text { chlorine cloud }(\mathrm{m})\end{array}$ & $\begin{array}{l}\text { Maximum width of } \\
\text { chlorine cloud }(\mathrm{m})\end{array}$ & $\begin{array}{l}\text { Cloud area of } \\
\text { chlorine }\left(\mathrm{m}^{2}\right)\end{array}$ & $\begin{array}{l}\text { Location point for } \\
100 \% \text { fatality }(\mathrm{m})\end{array}$ \\
\hline Rupture of & Spring & 56 & 805 & 310 & 175316 & 39.5 \\
vessel & Summer & 42 & 1220 & 360 & 333520 & 40 \\
& Autumn & 60 & 780 & 300 & 170505 & 40 \\
& Winter & 69 & 720 & 280 & 140824 & 39.5 \\
\hline Rupture of & Spring & 7.2 & 32.5 & 13.5 & 295 & Not exist \\
pipeline & Summer & 8.5 & 46.5 & 15 & 495 & Not exist \\
& Autumn & 7.5 & 34 & 13.5 & 330 & Not exist \\
& Winter & 6.9 & 25.5 & 12.5 & 222 & Not exist \\
\hline
\end{tabular}

\section{Discussion}

Environmental risks of geographical distribution of chemical plants have emerged gradually with increase of environmental pollution occasions. For instance, about 150,000 people were injured during the chlorine leaking accident on 16 April 2004 in the Tianyuan Chemical Plant in China (18). Such a report clearly reveals the importance of the present study. In the other hand, chlorination plays a critical role in protecting of drinking-water as it is one of the main achievements of our time in the protection of public health. Consequence analysis was used to evaluate the maximum downwind distance corresponding to the threshold with high risk in the accident appeared in chemical industries. Therefore, chlorine vessel of water treatment plant of Eyvan city from Ilam province, Iran, was investigated by PHAST tools. Its data expert is distances in which material released has high concentration and input data are operating and weather conditions.

According to the PHAST results, the worst scenario is related to rupture of chlorine vessel in summer because of the highest downwind distance of chlorine release in this state. This is because of the stability of weather condition in summer. As mentioned prior, the class stability of $\mathrm{C}$ is more than that of $\mathrm{B}$. It should be noted that the stable weather conditions have more downwind distance than the other conditions. From Figure 1, maximum and minimum cloud areas of the chorine covering around the source are occurred, respectively, in summer and winter for both scenarios. This is because class of stability differs for each season. When class of stability is $\mathrm{C}$, atmospheric condition is more stable and stability leads to covering a wide range of area around the source by chlorine release .

Moussa and Eid (19) investigated the risk management for chlorine release of a factory in Egypt. Their result showed the cloud concentration in release accident would arrive at $2500 \mathrm{~m}$ downwind distance from the vessel. In their case study a vessel with 30 tons of chlorine was used, which its volume is thirty times greater than the vessel used in the present study. Pandya et al (20) studied sensitivity of PHAST's atmospheric dispersion model for three toxic materials, namely, nitric oxide, ammonia, chlorine. Particularly for the case of chlorine, they found that the released cloud arrives to $82 \mathrm{~m}$ downwind distance from the source. Overally, the discrepancy between the results of the previous studies mentioned above (Moussa and Eid (19) and Pandya et al. (20)) and the present study is observed in terms of distance of chlorine 
release from the vessel, which is due to the different weather and operating conditions used in each case.

Figure 3 showed that maximum probability of fatality belongs to the first scenario with the value of $100 \%$ and minimum probability of fatality belongs to the second scenario with the value of $2.8 \%$. This discrepancy is due to differences in material volumes that have released. Therefore, the amount of chlorine in the vessel that is much more than the corresponding term in pipeline causes the rupture in vessel to be more fatal and damaging.

By bearing in mind the downwind distance of $1220 \mathrm{~m}$ corresponding to the threshold for irreversible impacts, considering this distance in the future programming is recommended to have a safe perimeters and consequently land-use planning. In addition, Haghnazarloo et al. (21) studied consequence modeling of a real rupture of toluene storage tank, more recently. They predicted dangerous distances for their case study. They also considered a presumed bund wall around the toluene vessel for more safety. This wall reduced the flash fire

\section{References}

1. Moro AM, Charao M, Brucker N, Bulcao R, Freitas F, Guerreiro G. Effects of low-level exposure to xenobiotics present in paints on oxidative stress in workers. Sci Total Environ. 2010; 408(20): 4461-7.

2. Tseng JM, Su TS, Kuo CY. Consequence evaluation of toxic chemical releases by ALOHA. Proc Eng. 2012; 45(1): 384-9.

3. Buckley RL, Hunter $\mathrm{CH}$, Werth DW, Whiteside MT, Chen KF, Mazzola CA. A case study of chlorine transport and fate following a large accidental release. Atmos Environ. 2012; 62(1):184-8.

4. Moloudi R, Esfahani JA. Modeling of gas release following pipeline rupture: Proposing non-dimensional correlation. extension. Similar to the Haghnazarloo et al. (21), it is proposed that the vessel containing chlorine should be covered by a bound wall to reduce the risks of accident.

\section{Conclusion}

Chlorine and its release consequences have a mortal effect in society. The PHAST software was used in this paper to modeling of chlorine release from water treatment plant of Eyvan city. All possible scenarios were considered for real chlorine plant and the results were presented in order to evaluate risk consequence of water treatment plant. The modeling results regarding the rupture of chlorine vessel in summer showed the worst possible release scenario because of covering the more distance compared to the other scenario. The probability of fatality is $100 \%$ at $40 \mathrm{~m}$ downwind distance from the vessel for all seasons of first scenario. Therefore, the surrounding land of the plant is nonresidential for this distance. Finally, it is suggested that the land around the unit should be haunted by a distance of $1220 \mathrm{~m}$.

J Loss Prevent Proc. 2014; 32(1):20717.

5. Botros KK, Geerligs J, Rothwell B, Carlson L, Fletcher L, Venton P.Transferability of decompression wave speed measured by a smalldiametershock tube to full size pipelines and implications for determining required fracture propagation resistance. Int J Press Vessel Pip. 2010; 87(12):681-95.

6. Egidi D, Foraboschi FP, Spadoni GE, Amendola A. The ARIPAR project: analysis of the major accident risks connected with industrial and transportation activities in the Ravenna area. Reliab Eng Syst Safe. 1995; 49(1):75-89. 
7. Hubert P, Pages P. Risk management for hazardous materials transportation: a local study in Lyons. Risk Anal. 1989;9(4):445-51.

8. Deaves DM, Gilham S, Mitchell BH, Woodburn P, Shepherd AM. Modeling of catastrophic flashing releases. J Hazard Mater.2001; 88(1):1-32.

9. Rao PG, Raghavan KV. Hazard and risk potential of chemical handling at ports. J Loss Prevent Proc. 1996; 9(3):199204.

10. Khan FI, Abbasi SA. Risk analysis of a typical chemical industry using ORA procedure. J Loss Prevent Proc. 2001;14(1):43-59.

11. Saat MR, Werth CJ, Schaeffer D, Yoon $\mathrm{H}$, Barkan CPL. Environmental risk analysis of hazardous material rail transportation. J Hazard Mater. 2014; 264(-):560-9.

12. Guideline for consequence analysis of chemical releases. 3rd ed. New York: American Institute of Chemical Engineers, Center of Chemical Process Safety; 1999.

13. Hanna S, Chang J. Gaps in toxic industrial chemical (TIC) model system. New York: 12th Conference on Harmonization within Atmospheric; 2008.

14. Galal-Gorchev H. Chlorine in water disinfection. Pure Appl Chem. 1996; 68(9):1731-5.
15. Hanna S, Dharmavaram S. Comparison of six widely-used dense gas dispersion models for three actual railcar accidents, Portugal: ITM2007; 2007.

16. Pandya N, Marsden E. Toxic release dispersion modeling with PHAST: parametric sensitivity analysis. Italy: 3rd International Conference on Safety \& Environment in Process Industry; 2008.

17. Guarnaccia J, Hoppe T, Off-site toxic consequence assessment: A Simplified modeling procedure and case study. $\mathrm{J}$ Hazard Mater. 2007; 159(1):177-84.

18. Yu Q, Zhang Y, Wang X, Ma WC, Chen LM. Safety distance assessment of industrial toxic releases based on frequency and consequence: A case study in Shanghai, China. J Hazard Mater. 2009; 168(2-3):955-61.

19. Moussa MI, Eid T. Risk management for chlorine producing factory in Egypt. Aust J Basic Appl Sci. 2007; 1(3):23948.

20. Pandya N, Gabas N, Marsden E. Sensitivity analysis of Phast's atmospheric dispersion model for three toxic materials (nitric oxide, ammonia, chlorine). J Loss Prevent Proc. 2012; 25(1):20-32.

21. Haghnazarloo H, Parvini M, Lotfollahi $\mathrm{MN}$. Consequence modeling of a real rupture of toluene storage tank. J Loss Prevent Proc. 2015; 37(1):11-8. 